\title{
General and abdominal obesity and incident asthma in adults: the HUNT study
}

\author{
Ben Brumpton*, Arnulf Langhammer*, Pål Romundstad*, \\ Yue Chen\# and Xiao-Mei Mai*
}

ABSTRACT: Measures of body mass index (BMI) and waist circumference define general obesity and abdominal obesity respectively. While high BMI has been established as a risk factor for asthma in adults, waist circumference has seldom been investigated.

To determine the association between BMI, waist circumference and incident asthma in adults, we conducted a prospective study $(n=23,245)$ in a population living in Nord-Trøndelag, Norway in 1995-2008.

Baseline BMI and waist circumference were measured and categorised as general obesity (BMI $\geqslant 30.0 \mathrm{~kg} \cdot \mathrm{m}^{2}$ ) and abdominal obesity (waist circumference $\geqslant 88 \mathrm{~cm}$ in females and $\geqslant 102 \mathrm{~cm}$ in males). Incident asthma was self-reported new-onset cases during an 11-yr follow-up period. Odds ratios for asthma associated with obesity were calculated using multivariable logistic regression.

General obesity was a risk factor for asthma in females (OR 1.96, 95\% Cl 1.52-2.52) and males (OR 1.84, 95\% CI 1.30-2.59). In females, after additional adjustment for BMI, abdominal obesity remained a risk factor for asthma development (OR 1.46, 95\% Cl 1.04-2.05). Abdominal obesity seems to increase the risk of incident asthma in females in addition to BMI, indicating that using both measures of BMI and waist circumference in females may be a superior clinical assessment for asthma risk than any measure alone.

KEYWORDS: Body mass index, prospective study, waist circumference

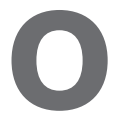
besity is defined as an excess of body fat and is commonly reflected by the measurements of body mass index (BMI) or waist circumference [1]. The prevalence and incidence of obesity have increased substantially in the last few decades [1]. The International Obesity Task Force estimates that globally 475 million adults are obese and 1 billion are overweight [2]. In the European Union this represents about $60 \%$ of the adult population [2]. Obesity is the fifth leading risk factor for global deaths and a strong risk factor for type 2 diabetes, cardiovascular disease and various types of cancer [1, 2]. Waist circumference is a measure of abdominal obesity and is associated with all-cause mortality $[3,4]$. Recent studies show that abdominal obesity is increasing at an even higher rate than general obesity [5]. The global obesity epidemic is projected to continue to rise and become the most significant cause of poor health.

A number of studies have prospectively investigated the association between obesity and asthma.
Overweight and obesity, as measured by BMI, have been found to increase the incidence of asthma in ences in the association are inconsistent [6]. However, BMI cannot distinguish between fat mass and muscle mass [7]. Most notably, BMI has limitations in predicting abdominal fat deposition, which is associated with reduced pulmonary function, metabolic syndrome and cardiovascular complications [8-10]. Abdominal subcutaneous and visceral fat deposits as measured by waist circumference may be metabolically different from other body fat, indicating a separate risk for common medical complications from peripheral fatness measured by BMI [8]. Only a few studies have investigated the association between abdominal obesity and asthma, most of which have been cross-sectional and have not taken BMI into consideration [11-17]. BMI and waist circumference are highly correlated [4]; to study the association between waist circumference and asthma, BMI should be considered. This study aimed to prospectively explore the a dose-dependent manner, but sex-related differ-

For editorial comments see page 253.

AFFILIATIONS

${ }^{*}$ Dept of Public Health and General Practice, Faculty of Medicine, Norwegian University of Science and Technology, Trondheim, Norway. "Dept of Epidemiology and Community Medicine, Faculty of Medicine, University of Ottawa, Ottawa, ON, Canada.

CORRESPONDENCE

B. Brumpton

Dept of Public Health and General Practice

NTNU Samfunnsmedisin

Level 5

Håkon Jarls Gate 11

Trondheim 7491

Norway

E-mail: ben.brumpton@ntnu.no

Received:

Jan 202012

Accepted after revision: May 092012

First published online:

May 312012 
associations of BMI and waist circumference with incident asthma in females and males.

\section{METHODS}

\section{Study population}

The Nord-Trøndelag Health Study (HUNT) is a population of females and males aged $\geqslant 19$ yrs living in the Nord-Trøndelag County $\left(22,463 \mathrm{~km}^{2}\right)$, Norway [18]. The county is situated in central Norway and typically has cold dry winters and mild summers. The county population in 1995 was 127,000, with the majority being Caucasians [18]. The county is characterised by several cities and farming towns, with the majority of the population residing in urban areas.

The cohort members in the current analysis participated in health surveys in 1995-1997 (HUNT 2) and in 2006-2008 (HUNT 3). Of the 65,215 participants who took part in HUNT 2 [19], 37,059 subjects also participated in HUNT 3, 11 yrs apart. We established a cohort population including all subjects who participated in both HUNT 2 and HUNT 3 and were aged $<65$ yrs in HUNT $3(n=25,616)$ (fig. 1). The age limit was set prior to conducting the study for two main reasons: 1) there is an increased possibility of misclassification of chronic obstructive pulmonary disease (COPD) as asthma in the elderly; and 2) obesity increases overall mortality [3,4]. If senior asthma patients who are obese are more likely to die compared with those who are not obese, it can result in an under-estimation of the association of interest. To study incident asthma, we excluded 56 participants with missing information on asthma in HUNT 2 and HUNT 3, and 1,994 subjects with asthma at baseline, leaving 23,566 subjects free from asthma in the study cohort.

\section{Measures of general and abdominal obesity}

Height, weight and waist circumference were measured in both surveys by trained nurses. Height was measured to the nearest $\mathrm{cm}$, and weight to the nearest half $\mathrm{kg}$. High BMI reflects general overweight and obesity. To calculate BMI, body weight in $\mathrm{kg}$ was divided by the squared value of the body height in $\mathrm{m}\left(\mathrm{kg} \cdot \mathrm{m}^{-2}\right)$. We adopted categories of BMI from the World Health Organization (WHO): BMI $<25.0 \mathrm{~kg} \cdot \mathrm{m}^{-2}$

Established cohort population:
1) Participated in both HUNT 2 and HUNT 3
2) Age <65 yrs in HUNT 3
$(n=25616 ; 100 \%)$

FIGURE 1. Flow chart of the analysis cohort. HUNT: Nord-Trøndelag Health Study; BMI: body mass index. (normal/underweight); BMI $25.0-29.9 \mathrm{~kg} \cdot \mathrm{m}^{-2}$ (general overweight) and $\mathrm{BMI} \geqslant 30.0 \mathrm{~kg} \cdot \mathrm{m}^{-2}$ (general obese) [20].

Waist circumference was measured to the nearest $\mathrm{cm}$, horizontally at the level of the umbilicus with the participants standing and arms hanging relaxed. Waist circumference is commonly used to reflect abdominal obesity. We adopted categories of waist circumference from the WHO [20] and LEAN et al. [21]: waist circumference $<80.0 \mathrm{~cm}$ (normal); waist circumference 80.0 $87.9 \mathrm{~cm}$ (abdominal overweight) and waist circumference $\geqslant 88.0 \mathrm{~cm}$ (abdominal obese) in females; waist circumference $<94.0 \mathrm{~cm}$ (normal); waist circumference 94.0-101.9 cm (abdominal overweight) and waist circumference $\geqslant 102.0 \mathrm{~cm}$ (abdominal obese) in males.

\section{Covariables}

Important variables at baseline were collected by self-administered questionnaires, including age (19-29, 30-39, 40-49, 50$55 \mathrm{yrs})$, years of education $(<10,10-12, \geqslant 13 \mathrm{yrs})$, current smoker (yes/no), physical activity $\left(<1,1-2, \geqslant 3 \mathrm{~h} \cdot\right.$ week $\left.^{-1}\right)$, family history of asthma (yes/no), social benefit recipient (yes/ no) and economic difficulty (yes/no). Family history of asthma included any family member (father, mother, brother or sister) with asthma. Social benefit included participants that received sick pay, rehabilitation benefits, retraining benefits, disability pension, old age pension, family income supplement, unemployment benefits, transitional benefits, widow's pension or any other benefit. Economic difficulties included participants that had difficulties meeting the cost of food, transport, and/or housing.

\section{Asthma outcome}

HUNT 2 and HUNT 3 included the same survey question on asthma, i.e. "Do you have or have you had asthma?" We defined incident asthma as "no" to this question in HUNT 2 and "yes" in HUNT 3. Self-reported asthma is commonly used in population based studies; this method has been rigorously evaluated and displays high sensitivity and specificity [22-24].

\section{Statistical methods}

The association of overweight and obesity with incident asthma was analysed in 23,245 participants with complete information on BMI, waist circumference and asthma. Pearson Chi-squared tests were used to compare baseline characteristics between females and males. Correlation of BMI and waist circumference was assessed using Pearson's correlation coefficient. We calculated the cumulative incidence of asthma risk according to the categories of overweight and obesity in logistic regression models, reporting odds ratios and the $95 \%$ confidence intervals. For test of trend, we calculated the association with incident asthma by treating the categories of BMI and waist circumference as ordinal variables. Odds ratios for cumulative incidence of asthma were also calculated with BMI and waist circumference as continuous variables. In the multivariable logistic regression analyses we adjusted for covariates including education, smoking status, physical activity, family history of asthma, social benefit, economic difficulty and age. Additionally, models for abdominal obesity were adjusted for BMI as a continuous variable to reduce the degrees of freedom in the model. We assessed the linearity of associations by introducing a term for the square of BMI or waist circumference in the logistic 
regression models and comparing models with and without the squared term in likelihood ratio tests. Tests for interaction between BMI categories $\left(<25.0,25.0-29.9, \geqslant 30.0 \mathrm{~kg} \cdot \mathrm{m}^{-2}\right)$ and sex were performed as likelihood ratio tests in logistic regression models. Subgroup analyses were completed by stratifying on age $(<40$ and $\geqslant 40 \mathrm{yrs})$, years of education $(<13$ and $\geqslant 13 \mathrm{yrs})$, physical activity $\left(<1,1-2\right.$ and $\geqslant 3 \mathrm{~h} \cdot$ week $\left.^{-1}\right)$, family history of asthma (yes/no), current smoking status (yes/no), social benefit (yes/no) and economic difficulties (yes/no) at baseline. To assess the robustness of our findings, we performed sensitivity analyses repeating the study with a stricter definition for incident asthma, i.e. self-reported asthma and use of asthma medication at HUNT 3 , without report of attacks of wheezing at baseline $(n=510)$ versus the reference group with no asthma and no wheeze at baseline or follow-up $(n=19,702)$. We also repeated the analyses excluding subjects who reported having chronic bronchitis, emphysema or COPD, i.e. "Have you had or do you have any of the following: chronic bronchitis, emphysema or COPD?" ( $n=22,857$ for analysis). We used STATA 11.1 for Windows, for all statistical analyses (StataCorp LP, College Station, TX, USA).

\section{Ethics}

The project was approved by the Regional Committee for Ethics in Medical Research. All participants signed informed consent for participation and the use of data in research.

\section{RESULTS}

Of the 23,245 adults in the analysis, the prevalence of general obesity at baseline was $12 \%$ in both sexes (table 1), but the prevalence of abdominal obesity was higher in females than in males $(17.5 \%$ versus $8.9 \%)$. There was a higher 11 -yr cumulative incidence of asthma in females compared with males $(4.1 \%$ versus $2.9 \%$ ). BMI and waist circumference values were highly correlated with Pearson correlation coefficient 0.89 in females and 0.84 in males $(\mathrm{p}<0.001$ for both correlations). A higher proportion of females reported family history of asthma, economic difficulty, receiving social benefit, smoking and more hours of physical activity than males.

BMI was associated with incident asthma in both sexes. After adjustment for covariates, the odds ratios for general obesity when compared to normal BMI were 1.96 (95\% CI 1.52-2.52) in females and 1.84 (95\% CI 1.30-2.59) in males (table 2). A doseresponse relationship between BMI and incident asthma was observed and the adjusted odds ratios for BMI categories were similar for females and males ( $p$ for interaction=0.66). The adjusted odds ratio for $\mathrm{BMI}$ (per $5 \mathrm{~kg} \cdot \mathrm{m}^{-2}$ ) as a continuous variable in females was 1.32 (95\% CI 1.19-1.45) and 1.38 (95\% CI 1.17-1.62) in males.

The adjusted odds ratios for abdominal obesity, compared to normal waist circumference, were 1.88 (95\% CI 1.51-2.34) in females and 1.55 (95\% CI 1.08-2.21) in males (table 3). Further adjustment for BMI, i.e. if subjects had similar BMI values, those with abdominal obesity yielded odds ratios of $1.46(95 \%$ CI 1.04-2.05) in females and 0.88 (95\% CI 0.53-1.47) in males. A dose-response relationship between waist circumference and incident asthma was observed in females ( $p$ for trend $=0.03$ ) but not in males ( $\mathrm{p}$ for trend=0.53) after adjustment for BMI. Odds ratios for incident asthma after adjustment for BMI rose steadily in females with increasing waist circumference, while odds ratios remained stable along the reference level line in

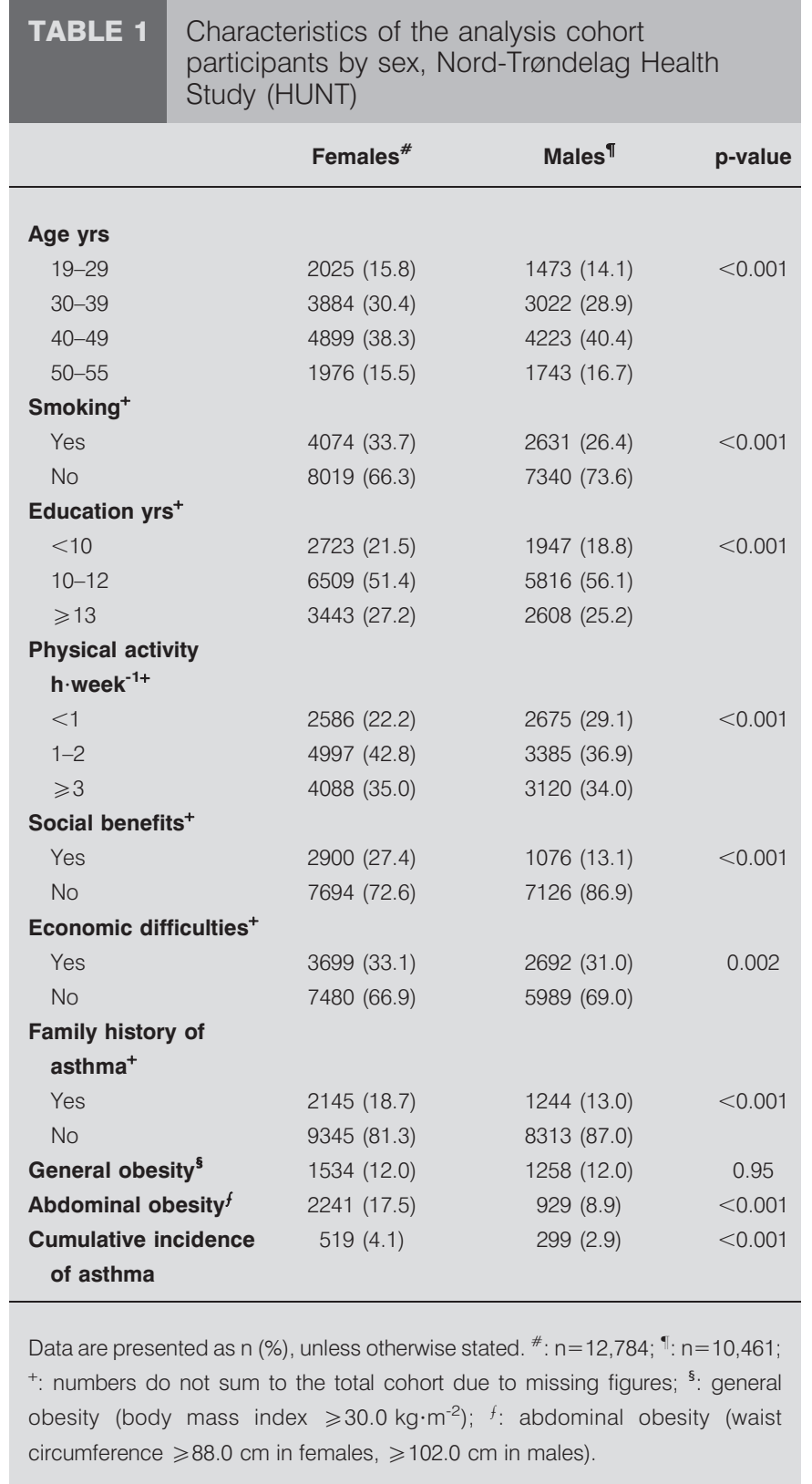

males (fig. 2). The odds ratios for waist circumference (per $10 \mathrm{~cm}$ ) as a continuous variable after adjustment for BMI were 1.23 (95\% CI 1.04-1.44) in females and 0.97 (95\% CI 0.76-1.23) in males.

A subgroup analysis by age revealed some variation in males (table 4). A higher odds ratio for incident asthma was observed in general obese males aged $\geqslant 40 \mathrm{yrs}$ (adjusted OR 2.35, 95\% CI $1.50-3.68$ ), compared to those aged $<40$ yrs (adjusted OR 1.28, $95 \%$ CI $0.71-2.32$ ). We also observed that general obese people with $\geqslant 13$ yrs education (adjusted OR 3.35, 95\% CI 1.91-5.90 in females and adjusted OR 3.70, 95\% CI 1.82-7.52 in males) were at a higher risk of developing asthma than those with $<13$ yrs education (OR 1.76, 95\% CI 1.32-2.33 in females and OR 1.56, 95\% CI 1.05-2.33 in males). The association in the subgroups of education $<10$ yrs and 10-12 yrs were similar; therefore these 
TABLE 2 General overweight and obesity at baseline in association with incident asthma in the Nord-Trøndelag Health Study (HUNT)

\begin{tabular}{|c|c|c|c|c|}
\hline & Subjects $n$ & Cases $\mathrm{n}(\%)$ & Crude OR $(95 \% \mathrm{Cl})$ & Adjusted OR $(95 \% \mathrm{Cl})^{\#}$ \\
\hline \multicolumn{5}{|l|}{ Females ${ }^{\pi}$} \\
\hline Normal BMI $<25.0 \mathrm{~kg} \cdot \mathrm{m}^{-2}$ & 6958 & $224(3.2)$ & 1.00 & 1.00 \\
\hline General overweight $25.0-29.9 \mathrm{~kg} \cdot \mathrm{m}^{-2}$ & 4292 & $195(4.5)$ & $1.43(1.18-1.74)$ & $1.44(1.18-1.76)$ \\
\hline General obesity $\geqslant 30.0 \mathrm{~kg} \cdot \mathrm{m}^{-2}$ & 1534 & $100(6.5)$ & $2.10(1.64-2.67)$ & $1.96(1.52-2.52)$ \\
\hline$p$-value for trend & & & 0.001 & 0.001 \\
\hline Normal BMI $<25.0 \mathrm{~kg} \cdot \mathrm{m}^{-2}$ & 3859 & $92(2.4)$ & 1.00 & 1.00 \\
\hline General overweight $25.0-29.9 \mathrm{~kg} \cdot \mathrm{m}^{-2}$ & 5344 & $149(2.8)$ & $1.17(0.90-1.53)$ & $1.21(0.93-1.58)$ \\
\hline General obesity $\geqslant 30.0 \mathrm{~kg} \cdot \mathrm{m}^{-2}$ & 1258 & $58(4.6)$ & $1.98(1.42-2.77)$ & $1.84(1.30-2.59)$ \\
\hline $\mathrm{p}$-value for trend & & & 0.001 & 0.001 \\
\hline $\mathrm{BMI}_{\text {continuous }}^{+}$ & 10461 & $299(2.9)$ & $1.44(1.23-1.70)$ & $1.38(1.17-1.62)$ \\
\hline
\end{tabular}

BMI: body mass index. ${ }^{\#}$ : adjusted for age, smoking, physical activity, education, family history of asthma, social benefit and economic difficulties at baseline;

$\because \mathrm{n}=12,784 ;^{+}$: BMl per 5-unit increase; s: $n=10,461$.

subgroups were combined to improve power in the analysis. We found no other strong variations within subgroups by physical activity, family history of asthma, smoking status, social benefit and economic difficulties.

The sensitivity analyses, using a stricter case definition of asthma, gave similar results to the original analyses. After adjustment for covariates, the odds ratios for general obesity when compared to normal BMI were 2.22 (95\% CI 1.63-3.03) in females and 1.89 (95\% CI 1.23-2.91) in males. The adjusted odds ratios for incident asthma associated with BMI continuous (per $5 \mathrm{~kg} \cdot \mathrm{m}^{-2}$ ) were 1.35 (95\% CI 1.20-1.53) in females and $1.42(95 \%$ CI $1.15-1.75)$ in males. After adjustment for covariates and BMI, the odds ratios for abdominal obesity when compared to normal waist circumference were 1.38 (95\% CI 0.90-2.13) in females and 0.59 (95\% CI 0.30-1.17) in males. The odds ratios for waist circumference continuous (per $10 \mathrm{~cm}$ ) were 1.25 (95\% CI 1.02-1.54) in females and 0.87 (95\% CI $0.64-1.21)$ in males. The sensitivity analyses excluding subjects with chronic bronchitis, emphysema or COPD gave similar results to the original analyses (data not shown).

\section{DISCUSSION}

In the 11-yr follow-up, we found that BMI-derived general overweight and obesity was a risk factor for incident asthma and

TABLE 3 Abdominal overweight and obesity at baseline in association with incident asthma in the Nord-Trøndelag Health Study (HUNT)

\begin{tabular}{|c|c|c|c|c|c|}
\hline & $\begin{array}{c}\text { Subjects } \\
n\end{array}$ & $\begin{array}{l}\text { Cases } \\
\text { n (\%) }\end{array}$ & $\begin{array}{l}\text { Crude OR } \\
(95 \% \mathrm{Cl})\end{array}$ & $\begin{array}{l}\text { Adjusted OR } \\
(95 \% \mathrm{Cl})^{\#}\end{array}$ & $\begin{array}{l}\text { Additionally adjusted for BMI } \\
\text { continuous OR }(95 \% \mathrm{Cl})\end{array}$ \\
\hline \multicolumn{6}{|l|}{ Females $\pi$} \\
\hline Normal waist circumference $<80.0 \mathrm{~cm}$ & 7666 & $253(3.3)$ & 1.00 & 1.00 & 1.00 \\
\hline Abdominal overweight $80.0-87.9 \mathrm{~cm}$ & 2877 & $122(4.2)$ & $1.30(1.04-1.62)$ & $1.30(1.04-1.62)$ & $1.17(0.91-1.50)$ \\
\hline Abdominal obesity $\geqslant 88.0 \mathrm{~cm}$ & 2241 & $144(6.4)$ & $2.01(1.63-2.48)$ & $1.88(1.51-2.34)$ & $1.46(1.04-2.05)$ \\
\hline \multicolumn{6}{|l|}{ Males $^{5}$} \\
\hline Normal waist circumference $<94.0 \mathrm{~cm}$ & 7073 & $184(2.6)$ & 1.00 & 1.00 & 1.00 \\
\hline Abdominal overweight $94.0-101.9 \mathrm{~cm}$ & 2459 & $74(3.0)$ & $1.16(0.88-1.53)$ & $1.15(0.87-1.52)$ & $0.89(0.65-1.23)$ \\
\hline Abdominal obesity $\geqslant 102.0 \mathrm{~cm}$ & 929 & $41(4.4)$ & $1.73(1.22-2.44)$ & $1.55(1.08-2.21)$ & $0.88(0.53-1.47)$ \\
\hline $\mathrm{p}$-value for trend & & & 0.003 & 0.02 & 0.53 \\
\hline Waist circumference continuous $^{+}$ & 10461 & $299(2.9)$ & $1.26(1.11-1.44)$ & $1.23(1.08-1.41)$ & $0.97(0.76-1.23)$ \\
\hline
\end{tabular}

BMI: body mass index. ${ }^{\#}$ : adjusted for age, smoking, physical activity, education, family history of asthma, social benefits and economic difficulties at baseline; ? $\mathrm{n}=12,784$; $^{+}$: waist circumference per 10-cm increase; ${ }^{\text {s: }} \mathrm{n}=10,461$. 

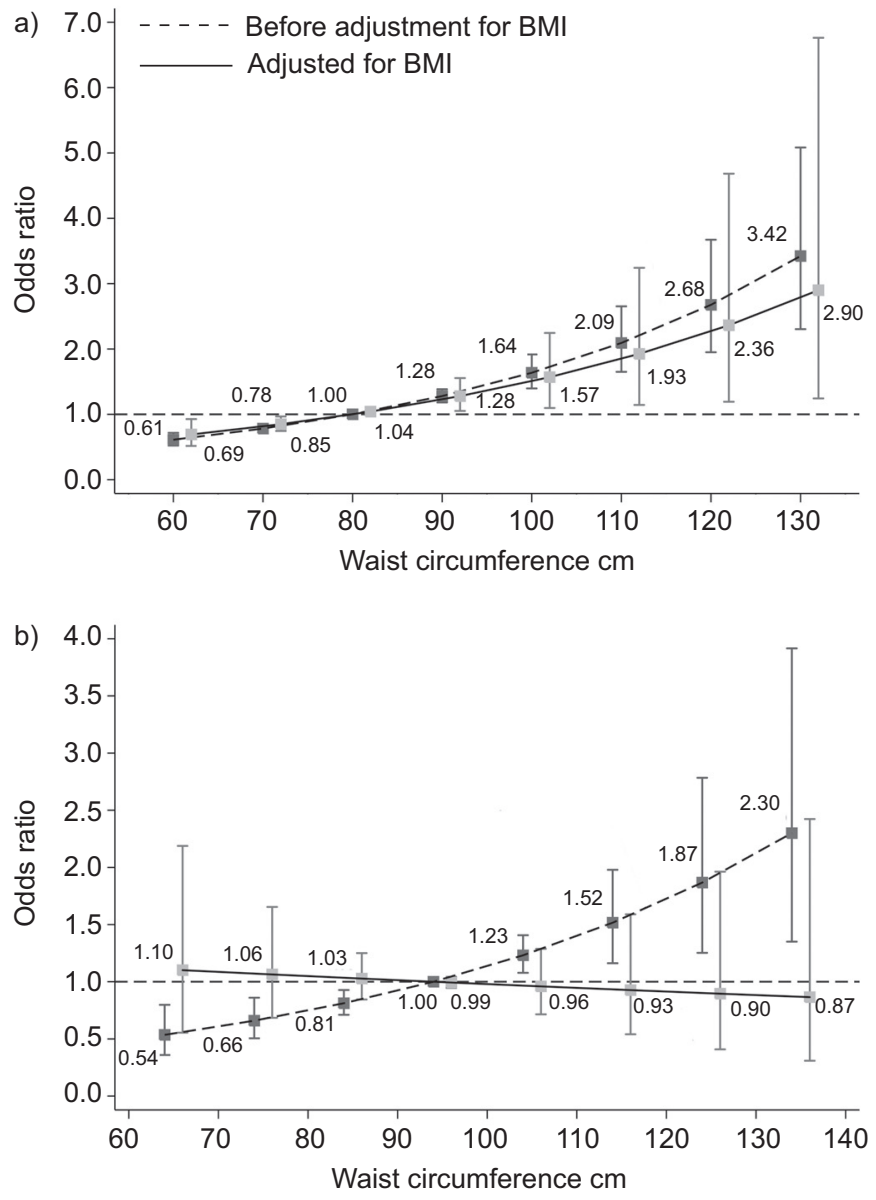

FIGURE 2. Waist circumference at baseline in association with incident asthma in the Nord-Trøndelag Health Study (HUNT), Norway. BMI: body mass index. ----: adjusted for age, smoking, physical activity, education, family history of asthma, social benefits and economic difficulties at baseline; —-: additionally adjusted for BMl as a continuous variable. The reference value for a) females is $80 \mathrm{~cm}$ and b) males is $94 \mathrm{~cm}$. Odds ratios for incident asthma before adjustment for $\mathrm{BMl}$ are at $10-\mathrm{cm}$ intervals from the reference values. Odds ratios for the BMI adjusted models are $2 \mathrm{~cm}$ above the unadjusted models to avoid overlapping the confidence intervals. Error bars indicate $95 \%$ confidence intervals.

there was no difference between females and males. In addition to BMI, we found that waist circumference derived abdominal obesity was a risk factor for incident asthma in females.

Our results on the BMI-derived obesity and asthma association are consistent with previous prospective studies, which found that BMI had a strong dose-response relationship with asthma development [6, 17, 25-30]. In a meta-analysis study, BEUTHER and SutHERLAND [6] analysed seven prospective studies $(n=333,102)$ evaluating BMI and incident asthma. The OR for incident asthma associated with general obesity was $1.92(95 \%$ CI 1.43-2.59) in this meta-analysis, similar to our finding in both females and males. Although BMI-derived obesity increases the incidence of asthma, sex-related differences in the association have been inconsistent $[6,12,13]$. The finding in our study suggests no difference between females and males in the association between general obesity and incident asthma in this Norwegian population. Our results conform to the findings of BEUTHER and SUTHERLAND [6] that obesity measured by BMI and incident asthma does not differ between sexes.

We observed that, after adjustment for BMI, being abdominaloverweight or obese remained a risk factor for incident asthma in females. This means that, when females had similar BMI values, those with abdominal obesity seemed to have an independent risk for asthma development. Therefore, large waist circumference, in addition to BMI, seems to add to the risk of developing asthma in females. Our observations indicate the use of both measures of BMI and waist circumference as a superior clinical assessment for asthma risk than any measure alone, particularly among females. This is one of the first prospective studies to observe the association of waist circumference in addition to BMI with incident asthma. A few studies have investigated the association of waist circumference and asthma [11-17], and considerably fewer studies have taken BMI into consideration in the association [15, 17]. Most of these studies are cross-sectional in nature, subject to reverse causality, and their observed association of waist circumference with asthma may be confounded by BMI [11-16]. In the Nurses' Health Study of 85,911 females, waist circumference was not found to be associated with incident asthma after adjustment for BMI [17]. Some of the differences could be related to the study having a shorter follow-up duration for waist circumference ( 2 yrs versus 11 yrs) and being carried out in different populations (USA versus Norway). Conversely, a cross-sectional study published recently provided supportive evidence for our finding. VON BEHREN et al. [15] studied 88,304 females in the California Teachers Study cohort and observed, when stratifying abdominal obesity by general obesity, an odds ratio for abdominally obese females without general obesity of 1.67 (95\% CI 1.51-1.85).

Several proposed explanations may support obesity as a risk factor for asthma development. SHORE and co-workers [31, 32] have suggested mechanistic mechanisms, including reduced airway size and also gastro-oesophageal reflux disease (GORD), sleep-disordered breathing (SDB), and obesity-associated cytokines, chemokines and energy-regulating hormones, to be underlying mechanisms for obesity-related asthma. The additional contribution of abdominal obesity in females, however, suggests that the distribution of adipose tissue may play a role in asthma development. Waist circumference reflects abdominal subcutaneous and visceral adipose tissue which may be metabolically different from peripheral fatness measured by BMI [8]. Visceral adipose tissue has a major role in metabolic and cardiovascular complications related to obesity $[8,10]$. Recent research has shed light on a positive association between metabolic syndrome and asthma prevalence [33]. There is also a possibility that the additional contribution of abdominal obesity on asthma is due to mechanical reasons. BEUTHER et al. [34] suggest that excess adipose tissue results in reduced lung volumes, rapid shallow breathing and reduced peripheral airway diameter, which may contribute to airway hyperresponsiveness and asthma. These mechanical mechanisms may be more pronounced in people with abdominal than with general obesity. As evidence, reduced pulmonary function has been demonstrated among subjects with large waist circumference irrespective of BMI [9]. Although non-significant, there seemed to be a sex-specific association between waist circumference and incident asthma after adjustment for BMI in our study. The 
TABLE 4 General overweight and obesity at baseline in association with incident asthma among males stratified by age $(<40$ and $\geqslant 40 \mathrm{yrs}$ ) in the Nord-Trøndelag Health Study (HUNT)

\begin{tabular}{clc}
\multicolumn{3}{c}{ Age $<40 \mathrm{yrs}^{\#}$} \\
\hline $\begin{array}{c}\text { Subjects } \\
\mathrm{n}\end{array}$ & Cases & Adjusted OR \\
$\mathrm{n}(\%)$ & $(95 \% \mathrm{Cl})^{+}$
\end{tabular}

\begin{tabular}{clc} 
& \multicolumn{3}{c}{ Age $\geqslant 40$ yrs $^{\top}$} \\
\hline $\begin{array}{c}\text { Subjects } \\
n\end{array}$ & Cases & Adjusted OR \\
& $n(\%)$ & $(95 \% \mathrm{Cl})^{+}$
\end{tabular}

\begin{tabular}{|c|c|c|c|c|c|c|}
\hline \multicolumn{7}{|l|}{ BMI } \\
\hline Normal BMI $<25.0 \mathrm{~kg} \cdot \mathrm{m}^{-2}$ & 1989 & $52(2.6)$ & 1.00 & 1870 & $40(2.1)$ & 1.00 \\
\hline General overweight $25.0-29.9 \mathrm{~kg} \cdot \mathrm{m}^{-2}$ & 2067 & $53(2.6)$ & $1.00(0.67-1.47)$ & 3277 & $96(2.9)$ & $1.45(0.99-2.11)$ \\
\hline General obesity $\geqslant 30.0 \mathrm{~kg} \cdot \mathrm{m}^{-2}$ & 439 & $15(3.4)$ & $1.28(0.71-2.32)$ & 8119 & $43(5.3)$ & $2.35(1.50-3.68)$ \\
\hline$p$-value for trend & & & 0.55 & & & 0.001 \\
\hline BMI continuous ${ }^{5}$ & 4495 & $120(2.7)$ & $1.18(0.90-1.53)$ & 5966 & $179(3.0)$ & $1.54(1.25-1.90)$ \\
\hline
\end{tabular}

BMI: body mass index. ${ }^{\#}: n=4,495 ; ": n=5,966{ }^{*}{ }^{+}$: adjusted for smoking, physical activity, education, family history of asthma, social benefits and economic difficulties at baseline; ${ }^{\text {s. }}$ BMI per 5-unit increase.

reasons behind this variation between sexes are unknown, but the mechanical theory may partially explain this sex specificity. Compared to males, females have a smaller airway size relative to lung size [13]. An additional reduction in airway size caused by abdominal obesity may disproportionately increase the susceptibility of females to asthma. Further studies are needed to confirm the occurrence of this difference and the potential mechanisms that underlie this association.

The subgroup analyses revealed that general obese males $\geqslant 40 \mathrm{yrs}$ were at higher risk of asthma compared to males $<40$ yrs. This may be due to changes in body type between these two subgroups. It has been suggested that BMI may be a poor indicator of general obesity in young males, who can have a high BMI due to high muscle mass [12]. This may explain the nonsignificant association between general obesity and incident asthma observed in males aged $<40$ yrs. In females and males we observed a stronger association between general obesity and asthma among those with $\geqslant 13$ yrs education compared to those with $<13$ yrs education. Previous studies have suggested that low education may be a surrogate measure of other risk factors associated with low economic status [35]. These underlying factors may play a greater role in asthma development in the less educated subgroup compared to the higher education group. The absence of these risk factors in highly educated adults may leave general obesity to play a greater role in the development of asthma. Reporting bias may also exist if adults with many years of education are more likely to seek medical attention and are diagnosed with asthma more regularly than adults with less education.

The major criticism of epidemiological studies of asthma and a limitation of our study is the lack of a true gold standard for asthma diagnosis. The use of self-reported asthma may have resulted in misclassification. Previous studies, however, suggest that validity and reliability of self-reported asthma are acceptable [22-24, 36]. To reduce misclassification we performed a sensitivity analysis with a stricter definition for asthma, i.e. selfreported asthma, no wheeze at baseline and asthma medication use at follow-up. To reduce misclassification of COPD with asthma we excluded people aged $>65$ yrs at follow-up in the study cohort. Additionally we performed analyses excluding participants who reported chronic bronchitis, emphysema or COPD in HUNT 3. COPD patients are more likely to be exsmokers. Adjustment for smoking status, i.e. current, ex-smoker and never-smoker, was tested and no change was observed in our estimates. In general the sensitivity analyses supported our original findings. Misclassification of obesity is also a major concern for epidemiological studies. In our study BMI and waist circumference were objectively measured to avoid reporting bias. Detection bias may also exist if obese people are more likely to come into contact with the healthcare system and are diagnosed more frequently with asthma than non-obese individuals. However, it is uncertain whether detection bias exists between obese and non-obese people [36]. Even though the detailed health survey allowed us to examine a large range of baseline characteristics, residual confounding from unknown characteristics may have limited our study. Dietary constituents may affect both obesity and incident asthma [28, 36], and this could not be evaluated in our study. Obesity has also been suggested to increase the risk of asthma through comorbidities [32], for example, GORD and SDB are important risk factors for asthma in obese people. We did not have measures of GORD and SDB in our data but previous studies suggested that GORD and SDB may be on the causative pathway between obesity and asthma [31,37]. In addition, because of the age limit ( $<65 \mathrm{yrs}$ ) set in our study, we need to be cautious when generalising these results. Our study population was relatively uniform in terms of ethnicity (97\% Caucasians) and environmental factors [18]. This would reduce the possibility of confounding by unmeasured factors. Importantly, the study design indicates the direction of the obesity-asthma association. It is also one of the first to prospectively study the impact of waist circumference on incident asthma taking BMI into consideration.

In summary, general obesity is a risk factor for incident asthma in both males and females. However, in females, measures of both general obesity and abdominal obesity may be superior for assessment of asthma risk than any measure alone. Further research is necessary to explore the mechanisms of how general and abdominal obesity contributes to asthma development. 


\section{SUPPORT STATEMENT}

This study was supported by the Research Council of Norway (project no. 201895/V50) and Faculty of Medicine at Norwegian University of Science and Technology, Trondheim, Norway.

\section{STATEMENT OF INTEREST}

None declared.

\section{ACKNOWLEDGEMENTS}

The Nord-Trøndelag Health Study (The HUNT Study) is a collaboration between HUNT Research Centre (Faculty of Medicine, Norwegian University of Science and Technology NTNU), Nord-Trøndelag County Council and the Norwegian Institute of Public Health.

\section{REFERENCES}

1 World Health Organization. Obesity and Overweight. www.who. int/mediacentre/factsheets/fs311/en/Date last accessed: January 20, 2012. Date last updated: March 2011.

2 International Association for the Study of Obesity. The Global Epidemic. www.iaso.org/iotf/obesity/obesitytheglobalepidemic/ Date last accessed: December 8, 2012.

3 Bigaard J, Frederiksen K, Tjonneland A, et al. Waist circumference and body composition in relation to all-cause mortality in middleaged men and women. Int J Obes 2005; 29: 778-784.

4 Pischon T, Boeing H, Hoffmann K, et al. General and abdominal adiposity and risk of death in Europe. $N$ Engl J Med 2008; 359: 2105-2120.

5 Walls HL, Stevenson CE, Mannan HR, et al. Comparing trends in BMI and waist circumference. Obesity 2011; 19: 216-219.

6 Beuther DA, Sutherland ER. Overweight, obesity, and incident asthma - a meta-analysis of prospective epidemiologic studies. Am J Resp Crit Care 2007; 175: 661-666.

7 Ness-Abramof R, Apovian CM. Waist circumference measurement in clinical practice. Nutr Clin Pract 2008; 23: 397-404.

8 Arner P. Not all fat is alike. Lancet 1998; 351: 1301-1302.

9 Chen Y, Rennie D, Cormier YF, et al. Waist circumference is associated with pulmonary function in normal-weight, overweight, and obese subjects. Am J Clin Nutr 2007; 85: 35-39.

10 Janssen I, Katzmarzyk PT, Ross R. Waist circumference and not body mass index explains obesity-related health risk. Am J Clin Nutr 2004; 79: 379-384.

11 Del-Rio-Navarro BE, Fanghanel G, Berber A, et al. The relationship between asthma symptoms and anthropometric markers of overweight in a Hispanic population. J Invest Allerg Clin 2003; 13: $118-123$

12 Kronander UN, Falkenberg M, Zetterstrom O. Prevalence and incidence of asthma related to waist circumference and BMI in a Swedish community sample. Resp Med 2004; 98: 1108-1116.

13 Chen Y, Rennie D, Cormier Y, et al. Sex specificity of asthma associated with objectively measured body mass index and waist circumference - The Humboldt study. Chest 2005; 128: 3048-3054.

14 Appleton SL, Adams RJ, Wilson DH, et al. Central obesity is associated with nonatopic but not atopic asthma in a representative population sample. J Allergy Clin Immun 2006; 118: 1284-1291.

15 Von Behren J, Lipsett M, Horn-Ross PL, et al. Obesity, waist size and prevalence of current asthma in the California Teachers Study cohort. Thorax 2009; 64: 889-893.
16 Bustos $\mathrm{P}$, Amigo $\mathrm{H}$, Oyarzun $\mathrm{M}$, et al. Is there a causal relation between obesity and asthma? Evidence from Chile. Int J Obes 2005; 29: 804-809.

17 Camargo CA Jr, Weiss ST, Zhang S, et al. Prospective study of body mass index, weight change, and risk of adult-onset asthma in women. Arch Intern Med 1999; 159: 2582-2588.

18 Holmen JMK, Krüger $\varnothing$, Langhammer A, et al. The NordTrøndelag Health Study 1995-97 (HUNT 2): objectives, contents, methods and participation. Norsk Epidemiol 2003; 13: 19-32.

19 Norwegian University of Science and Technology. The NørdTrøndelag Health Study. www.ntnu.edu/hunt Date last accessed: December 8, 2012.

20 World Health Organization. Waist Circumference and Waist-hip Ratio: Report of a WHO Expert Consultation, Geneva, 8-11 December 2008.

21 Lean ME, Han TS, Morrison CE. Waist circumference as a measure for indicating need for weight management. BMJ 1995;311: 158-161.

22 Toren K, Brisman J, Jarvholm B. Asthma and asthma-like symptoms in adults assessed by questionnaires. A literature review. Chest 1993; 104: 600-608.

23 de Marco R, Cerveri I, Bugiani M, et al. An undetected burden of asthma in Italy: the relationship between clinical and epidemiological diagnosis of asthma. Eur Respir J 1998; 11: 599-605.

24 Kilpelainen $\mathrm{M}$, Terho EO, Helenius $\mathrm{H}$, et al. Validation of a new questionnaire on asthma, allergic rhinitis, and conjunctivitis in young adults. Allergy 2001; 56: 377-384.

25 Chen $Y$, Dales R, Tang M, et al. Obesity may increase the incidence of asthma in women but not in men: longitudinal observations from the Canadian National Population Health Surveys. Am J Epidemiol 2002; 155: 191-197.

26 Ford ES, Mannino DM, Redd SC, et al. Body mass index and asthma incidence among USA adults. Eur Respir J 2004; 24: 740-744.

27 Gunnbjornsdottir MI, Omenaas E, Gislason T, et al. Obesity and nocturnal gastro-oesophageal reflux are related to onset of asthma and respiratory symptoms. Eur Respir J 2004; 24: 116-121.

28 Huovinen E, Kaprio J, Koskenvuo M. Factors associated to lifestyle and risk of adult onset asthma. Resp Med 2003; 97: 273-280.

29 Nystad W, Meyer HE, Nafstad P, et al. Body mass index in relation to adult asthma among 135,000 Norwegian men and women. Am J Epidemiol 2004; 160: 969-976.

30 Romieu I, Avenel V, Leynaert B, et al. Body mass index, change in body silhouette, and risk of asthma in the E3N cohort study. Am J Epidemiol 2003; 158: 165-174.

31 Shore SA, Johnston RA. Obesity and asthma. Pharmacol Ther 2006; 110: 83-102

32 Shore SA. Obesity and asthma: implications for treatment. Curr Opin Pulm Med 2007; 13: 56-62.

33 McGinley B, Punjabi NM. Obesity, metabolic abnormalities, and asthma: establishing causal links. Am J Respir Crit Care Med 2011 183: 424-425.

34 Beuther DA, Weiss ST, Sutherland ER. Obesity and asthma. Am J Respir Crit Care Med 2006; 174: 112-119.

35 Boggs DA, Rosenberg L, Cozier YC, et al. General and abdominal obesity and risk of death among black women. N Engl J Med 2011; 365: 901-908.

36 Ford ES. The epidemiology of obesity and asthma. J Allergy Clin Immunol 2005; 115: 897-909.

37 Kasasbeh A, Kasasbeh E, Krishnaswamy G. Potential mechanisms connecting asthma, esophageal reflux, and obesity/sleep apnea complex - a hypothetical review. Sleep Med Rev 2007; 11: 47-58. 